\title{
Head Growth and Intelligence from Birth to Adulthood in Very Preterm and Term Born Individuals
}

\author{
Julia Jaekel, ${ }^{1,2}$ Christian Sorg, ${ }^{3,4,5}$ Josef Baeuml, ${ }^{3,4,5}$ Peter Bartmann, ${ }^{6}$ And Dieter Wolke ${ }^{2,7}$ \\ ${ }^{1}$ Department of Child and Family Studies, University of Tennessee, Knoxville, Tennessee \\ ${ }^{2}$ Department of Psychology, University of Warwick, Coventry, United Kingdom \\ ${ }^{3}$ TUM-Neuroimaging Center Technische Universität München TUM, Munich, Germany \\ ${ }^{4}$ Department of Neuroradiology Technische Universität München TUM, Munich, Germany \\ ${ }^{5}$ Department of Psychiatry of Klinikum rechts der Isar, Technische Universität München TUM, Munich, Germany \\ ${ }^{6}$ Department of Neonatology, University Hospital Bonn, Bonn, Germany \\ ${ }^{7}$ Division of Mental Health and Wellbeing, Warwick Medical School, University of Warwick, Coventry, United Kingdom
}

(Received March 14, 2018; Final Revision July 19, 2018; Accepted August 23, 2018; First Published Online November 14, 2018)

\begin{abstract}
Objectives: The aim of this study was to investigate the effects of infant and toddler head growth on intelligence scores from early childhood to adulthood in very preterm ( $<32$ weeks gestational age; VP) and/or very low birth weight (<1500 g; VLBW) and term born individuals. Methods: 203 VP/VLBW and 198 term comparisons were studied from birth to adulthood as part of the prospective geographically defined Bavarian Longitudinal Study (BLS). Head circumference was assessed at birth; 5, 20 months; and 4 years of age. Intelligence was assessed with standardized tests in childhood (6 and 8 years: K-ABC) and at 26 years (Wechsler Adult Intelligence Scale, WAIS). Structural equation modeling (SEM) was used to model the effect of head growth on IQ. Results: On average, VP/VLBW had lower head circumference at birth $(27.61 \mathrm{~cm} v s .35 .11 \mathrm{~cm}$, mean difference $7.49,95 \%$ confidence interval [7.09-7.90]) and lower adult intelligence scores (88.98 vs. 102.54, mean difference 13.56 [10.59-16.53]) than term born comparison individuals. Head circumference at birth (e.g., total effect $\beta=.48 ; p<.001$ for adult IQ) and head growth in childhood predicted intelligence development from age 6 to 26 years in both VP/VLBW and term born individuals (70\% of variance in adult IQ explained by full model). Effects of gestation and birth weight on intelligence were fully mediated by head circumference and growth. Conclusions: This longitudinal investigation from birth to adulthood indicates head growth as a proxy of brain development and intelligence. Repeated early head circumference assessment adds valuable information when screening for long-term neurocognitive risk. (JINS, 2019, 25, 48-56)
\end{abstract}

Keywords: Early childhood, Gestational age, Prospective longitudinal study, Brain development, Birth weight, Wechsler Adult Intelligence Scale, RECAP preterm

\section{INTRODUCTION}

Very preterm $(<32$ weeks gestational age; VP) and very low birth weight $(<1500 \mathrm{~g}$, VLBW) infants grow up with lifelong risks for neurocognitive impairment (Breeman, Jaekel, Baumann, Bartmann, \& Wolke, 2015; Eryigit Madzwamuse, Baumann, Jaekel, Bartmann, \& Wolke, 2015). Early identification allows timely provision of resources. Follow-up after VP/VLBW birth is a general standard in many Western countries (Doyle et al., 2014). However, assessing cognitive development through descriptive behavioral data is time

Correspondence and reprint requests to: Dieter Wolke, Department of Psychology, University of Warwick, Coventry CV4 7AL, UK. E-mail: d.wolke@ warwick.ac.uk consuming and expensive (Aslin \& Fiser, 2005; Hack et al., 2005). Repeated head circumference assessments may be a cost-effective indicator of brain development (Bartholomeusz, Courchesne, \& Karns, 2002; Cheong et al., 2008; Garcia-Alix, Saenz-de Pipaon, Martinez, SalasHernandez, \& Quero, 2004). Regional brain and cortical growth is significantly associated with brain maturation (Makropoulos et al., 2016), generally indicating that size matters.

Head circumference is measured in infancy in most countries, but its predictive validity remains controversial (Wright \& Emond, 2015). At term, preterm infants have smaller whole brain volumes than term born infants (Ball et al., 2012; Makropoulos et al., 2016). Researchers argue that head growth between birth and 2 years is critical for intellectual 
development (Räikkönen et al., 2009) and studies of preterm populations have documented the value of head growth as a predictor of long-term neurocognitive abilities (Sammallahti et al., 2017, 2014). Accelerated postnatal head growth suggests catch up after prenatal restraint (Cockerill, Uthaya, Doré, \& Modi, 2006), but may not compensate for poor earlier growth after infancy (Gale, O'Callaghan, Bredow, \& Martyn, 2006). Thus, it is important to investigate whether there are certain time windows of head growth that matter most for later IQ development.

In clinical practice, individual head growth is usually documented by plotting raw head circumference values on age-standardized growth chart curves, by converting raw values into standard scores, or by categorizing scores (Fenton \& Kim, 2013). This is done to (clinically) identify individuals who grow at a substantially slower than average rate. Instead, growth over time may be assessed with latent class growth curve analyses to identify how the growth rate across all individuals (i.e., head growth) affects growth in another dimension (i.e., IQ). Structural equation modeling (SEM) has been proposed as the most appropriate approach in the context of additional factors (e.g., gestational age, birth weight) (Usami, Hayes, \& McArdle, 2017).

Our aims were (i) to investigate VP/VLBW and term born individuals' head growth from birth to 4 years and intelligence in childhood and adulthood, and (ii) to determine the specific timing of head growth that matters for intelligence development.

\section{METHODS}

\section{Design}

Participants were all VP and/or VLBW infants and an equally sized group of healthy term comparisons born in a geographically defined area of South Bavaria (Germany) between January 1985 and March 1986 as part of the prospective whole population Bavarian Longitudinal Study (BLS). The current study uses data collected at birth; at 5 and 20 months; and at 4, 6, 8, and 26 years of age.

\section{Standard protocol approvals and patient consents}

This research was completed in accordance with the Helsinki Declaration. Original ethical approval was obtained from the University of Munich Children's Hospital and the Landesärztekammer Bayern. Ethical approval for the adult follow-up was granted by the Ethical Board of the University Hospital Bonn (reference 159/09). Informed written consent was provided by parents within $48 \mathrm{hr}$ of their child's birth and all participants gave fully informed written consent for the adult assessment.

\section{Participants}

This study assesses a whole population sample of $682 \mathrm{VP} /$ VLBW individuals (Wolke \& Meyer, 1999). Of this cohort,
411 VP/VLBW were presumed alive, living in Germany, and eligible for inclusion at 26 years of age, and $260(63.3 \%)$ participated in the adult assessment (see Appendix Figure 1). The BLS VP/VLBW participants did not differ from VP/ VLBW adults who dropped out in terms of GA, BW, duration of hospitalization, gender, maternal age, parental marital status, and childhood cognitive scores, but had fewer prenatal complications and were of higher socioeconomic status (SES) (Eryigit Madzwamuse et al., 2015).

Of 916 healthy term-born comparison infants at birth, 350 were selected and stratified to match the VP/VLBW participants at the 6 years follow-up assessment. Of these, 308 individuals were eligible for inclusion and 229 (74.4\%) participated at 26 years (Eryigit Madzwamuse et al., 2015). Only participants who had complete childhood and adulthood IQ data (203 VP/VLBW and 198 term comparisons) were included in the current analyses.

\section{Head circumference}

Head circumference (in centimeters) was assessed by trained research nurses during clinical assessments at birth; 5 and 20 months; and at 4, 6, and 8 years of age. At 5 and 20 months, examination ages were corrected for gestational age at birth. $\mathrm{HC}$ was measured twice at each assessment and the average score was recorded. Raw HC scores and standardized scores are reported in Table 1. Raw scores are used in main analyses to investigate separate contributions of gestation and birth weight in our statistical models.

\section{Biological and demographic characteristics}

Gestational age (weeks, range: VP/VLBW $=25-36$, term comparisons $=37-42$ ) and birth weight (grams, range: VP/ $\mathrm{VLBW}=630-2590$, term comparisons $=2120-5050)$ were coded from Bavarian perinatal survey forms at birth (Zander, Holzmann, \& Selbmann, 1989). Family SES at birth was assessed as a weighted composite score of parents' education and occupation (Bauer, 1988).

\section{Neurocognitive assessments}

Cognitive development (i.e., intelligence) was assessed longitudinally by psychologists with standardized tests in childhood and adulthood (Breeman et al., 2015). At age 20 months, children were administered the Griffiths' Mental Development Scales Developmental Quotient (DQ) items (Brandt, 1983). At 6 and 8 years, IQ was assessed with the German version of the Kaufman Assessment Battery for Children (K-ABC) (Melchers \& Preuss, 1991). Reliability and construct validity of the $\mathrm{K}-\mathrm{ABC}$ are high [e.g., 0.70 correlation with the Wechsler Intelligence Scale for ChildrenRevised (WISC-R) total score] (Melchers \& Preuss, 1991). At 26 years, age-normed Full-Scale IQ was assessed with a short German version of the Wechsler Adult Intelligence Scale (WAIS III) (Von Aster, Neubauer, \& Horn, 2006). In our models, VP/VLBW individuals' DQ and IQ data from different ages are directly compared to healthy term born 
Table 1. Descriptive characteristics of the VP/VLBW and term participants from birth to age 26 years

\begin{tabular}{|c|c|c|c|c|}
\hline & $\begin{array}{l}\text { VP/VLBW } \\
(n=203)\end{array}$ & $\begin{array}{l}\text { Term comparisons } \\
\qquad(n=198)\end{array}$ & $\begin{array}{l}\text { Mean difference } \\
\qquad(95 \% \mathrm{CI})\end{array}$ & $p$-Value \\
\hline Birth weight (g) & $1318(320)$ & $3368(453)$ & $2050(1973-2127)$ & $<.001$ \\
\hline Gestational age (weeks) & $30.40(2.05)$ & $39.65(1.19)$ & $9.25(8.92-9.58)$ & $<.001$ \\
\hline Sex (\% male) & 53.2 & 47.9 & $1.09^{\mathrm{a}}$ & .296 \\
\hline Family SES ( $1=$ lowest, $6=$ highest $)$ & $2.61(1.42)$ & $2.85(1.54)$ & $0.24(0.05-0.54)$ & .100 \\
\hline Head circumference at birth $(\mathrm{cm})$ & $27.61(2.39)$ & $35.11(1.34)$ & $7.49(7.09-7.90)$ & $<.001$ \\
\hline Head growth, birth to 5 months $(\mathrm{cm})$ & $14.57(2.57)$ & $7.71(1.21)$ & $-6.86(-7.28-(-6.44)$ & $<.001$ \\
\hline Head growth, 5 to 20 months $(\mathrm{cm})$ & $5.68(1.43)$ & $5.72(0.94)$ & $0.05(-0.30-0.20)$ & .722 \\
\hline Head growth, birth to 20 months $(\mathrm{cm})$ & $20.24(2.45)$ & $13.44(1.48)$ & $-6.81(-7.23-(-6.39))$ & $<.001$ \\
\hline Head growth, 20 months to 4 years $(\mathrm{cm})$ & $2.21(1.01)$ & $2.64(0.96)$ & $0.43(0.22-0.63)$ & $<.001$ \\
\hline Standardized head circumference, birth $^{\mathrm{b}}$ & $-5.35(2.00)$ & $0.77(1.06)$ & $6.12(5.79-6.45)$ & $<.001$ \\
\hline Standardized head circumference, 5 months ${ }^{\mathrm{b}}$ & $0.12(1.39)$ & $0.67(0.83)$ & $0.56(0.32-0.79)$ & $<.001$ \\
\hline Standardized head circumference, 20 months ${ }^{\mathrm{b}}$ & $0.51(1.24)$ & $1.05(0.93)$ & $0.54(0.32-0.77)$ & $<.001$ \\
\hline Standardized head circumference, 4 years ${ }^{\text {b }}$ & $-0.09(1.16)$ & $0.71(0.94)$ & $0.80(0.58-1.02)$ & $<.001$ \\
\hline DQ at 20 months & $95.37(17.82)$ & $107.02(6.47)$ & $11.65(14.33-8.96)$ & $<.001$ \\
\hline IQ at 6 years & $89.74(14.15)$ & $102.32(11.27)$ & $12.58(9.93-15.23)$ & $<.001$ \\
\hline IQ at 8 years & $92.31(15.22)$ & $102.91(9.66)$ & $10.60(8.01-13.20)$ & $<.001$ \\
\hline IQ at 26 years & $88.98(17.33)$ & $102.54(12.60)$ & $13.56(10.59-16.53)$ & $<.001$ \\
\hline
\end{tabular}

Note. Data are presented as mean (standard deviation) if not indicated otherwise; all assessments at 5 and 20 months were adjusted for gestational age at birth. ${ }^{\mathrm{a}} \chi^{2}$-Value.

${ }^{\mathrm{b}}$ Standardized according to current international World Health organization (WHO) child growth standard scores (WHO, 2007).

$\mathrm{CI}=$ confidence interval; $\mathrm{DQ}=$ developmental quotient; $\mathrm{IQ}=$ intelligence quotient; $\mathrm{SES}=$ socioeconomic status; VLBW $=$ very low birth weight; VP $=$ very preterm.

comparison individuals' DQs and IQs at each assessment point.

\section{Statistical approach}

Data were analyzed with SPSS 23 and Amos 24 (Armonk, NY: IBM Corp.). Structural Equation Modeling (SEM) was used to simultaneously test direct and indirect associations between head circumference and growth, and intelligence to 26 years of age. Gestational age, birth weight, and family SES were included as additional predictors of interest. In the initial, full model, all variables and the potential paths between each measure were included (see Appendix Figure 2). Model fit values were then used to identify the best fitting and most parsimonious final model, indicating the timing of head growth that matters most for intelligence development. Final model results are presented combined for VP/VLBW and term comparisons (Model 1), and as separate multiple-group models (Models 2 and 3).

\section{RESULTS}

On average, VP/VLBW had lower head circumference at birth, lower head growth from 20 months to 4 years, and lower intelligence scores than term born comparison individuals (Table 1). However, VP/VLBW had higher head growth from birth to 5 months and, on average, from birth to 20 months than term born comparison infants, both assessments were scheduled corrected for gestational age.

The initial, full model did not have sufficient fit $\left[\chi^{2}=80.44\right.$ $(d f=16) ; p<.001$; comparative fit index $(\mathrm{CFI})=.983$; root mean square error of approximation $($ RMSEA $)=1.00(90 \%$ confidence interval (CI) [.079 to .123]; $p$ of close fit $(\mathrm{PCLOSE})=.000 ;$ Appendix Figure 2] and was thus reduced to the best fitting, most parsimonious Model 1 (Figure 1). In particular, there was no added value in assessing head growth from birth to 5 months and then from 5 to 20 months separately; thus, growth from birth to 20 months was collapsed into one variable. Moreover, cognitive development at 20 months was less accurately predicted by infants' head growth than IQ at $6+$ years.

Model 1 showed that head circumference at birth and head growth in childhood predicted intelligence development from age 6 to 26 years in both VP/VLBW and term born individuals. Effects of gestation and birth weight on intelligence were found to be fully mediated by head circumference and growth (i.e., indirect effects) while family SES directly predicted intelligence. Table 2 shows detailed direct, indirect, and total effects for all variables in the model. The total variance explained $\left(R^{2}\right)$ in intelligence was $29 \%$ at 6 years, $73 \%$ at 8 years, and $70 \%$ at 26 years of age. Overall model fit was excellent with $\chi^{2}=19.85(d f=16)$; $p<.227 ; \mathrm{CFI}=.999 ; \mathrm{RMSEA}=.025$ (90\% CI [.000-.055]; PCLOSE $=.907$.

Since part of the explained variance in adult IQ was carried by childhood IQ (i.e., longitudinal stability of IQ), we also explored how much variance was explained if only the isolated effects of $\mathrm{HC}$ at birth and head growth were used to predict adult IQ. A substantial $R^{2}=.24$ were explained just by $\mathrm{HC}$ at birth and early head growth in the total sample $\left(R^{2}=.22\right.$ in VP/VLBW and $R^{2}=.02$ in healthy term control individuals, respectively). 


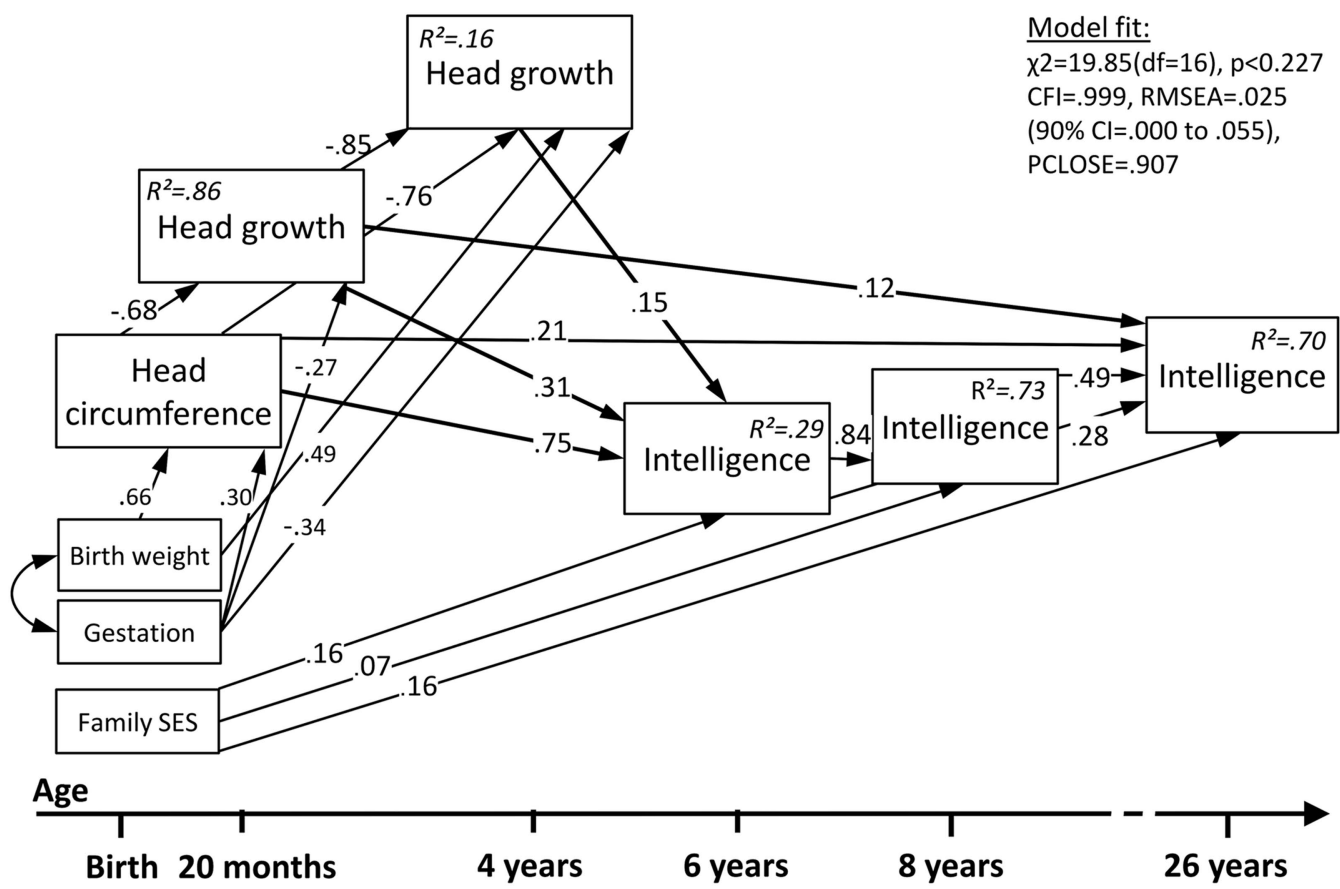

Fig. 1. Final structural equation Model 1. Neurocognitive cascades of head growth and intelligence from birth to adulthood in VP/VLBW and term born individuals $(n=401)$.

To test if the associations between head growth and intelligence were different among VP/VLBW compared with term comparison individuals, we ran the same SEM separately as a multiple-group model. As before, head circumference at birth, head growth from birth to 20 months, and from 20 months to 4 years predicted intelligence development from age 6 to 26 years in VP/VLBW and term born individuals, but the path coefficients were slightly different (Figures 2 and 3).

Model 2 shows that among VP/VLBW, head circumference at birth and head growth in early childhood directly predicted intelligence at age 6 , while there were only indirect effects on intelligence at 8 and 26 years. The total variance explained in intelligence was $22 \%$ at 6 years, $79 \%$ at 8 years, and $73 \%$ at 26 years.

Model 3 shows that among term comparisons, only head growth from birth to 20 months directly predicted intelligence at age 26. The total variance explained in term comparison individuals' intelligence was lower with $9 \%$ at 6 years, $53 \%$ at 8 years, and $53 \%$ at 26 years.

As before, model fit was excellent with $\chi^{2}=19.78(d f=16)$; $p<.230$; CFI $=.999$; RMSEA $=.024$ (90\% CI [.000-.053]; PCLOSE $=.924$; and effects of gestation and birth weight on intelligence were fully mediated by head circumference and growth while family SES directly predicted intelligence.

\section{DISCUSSION}

This longitudinal investigation from birth to adulthood confirms that early head growth as a proxy of brain development predicts later intelligence in VP/VLBW but also in term born individuals. Larger head circumference at birth and higher head growth during the first 4 years predicted IQ from age 6 to 26 years in both VP/VLBW and term born individuals while effects of gestation and birth weight on intelligence

Table 2. Standardized direct, indirect, and total effects (i.e., path coefficients) of the predictors in the final overall Model $1(N=401)$

\begin{tabular}{|c|c|c|c|c|c|c|}
\hline & $\mathrm{HC}$ at birth & HG birth-20 months & HG 20 months $-4 y$ & IQ 6y & IQ 8y & IQ 26y \\
\hline Birth weight & $.66 / .00 / .66$ & $.00 /-.45 /-.45$ &.$\underline{.49 /-.12 / .38}$ & $.00 / .41 / .41$ & $.00 / .35 / .35$ & $.00 / .37 / 37$ \\
\hline Gestational age & $. \overline{30} / .00 / .30$ & $-. \overline{27} /-.20 /-.48$ & $-. \overline{34} / .18 /-.16$ & $. \overline{00} / .05 / .05$ & $. \overline{00} / .04 / .04$ & $. \overline{00} / .04 / .04$ \\
\hline Family SES & $. \overline{00} / .00 / .00$ & $. \overline{.00} / .00 / .00$ & $. \overline{00} / .00 / .00$ & $. \overline{16} / .00 / .16$ &.$\overline{07 / .13 / .21}$ & $. \overline{16} / .14 / .30$ \\
\hline $\mathrm{HC}$ at birth & $-/-/-$ & $-. \overline{68} / .00 /-.68$ & $-. \overline{76} / .58 /-.18$ & $. \overline{75} /-.24 / .51$ & $. \overline{00} / .43 / .43$ & $. \overline{21} / .27 / .48$ \\
\hline HG birth-20 months & $-/-/-$ & $-/-/-$ & $-. \overline{85} / .00 /-.85$ & $. \overline{31} /-.13 / .18$ & $. \overline{00} / .15 / .15$ & $. \overline{12} / .13 / .25$ \\
\hline HG 20 months $-4 y$ & $-/-/-$ & $-/-/-$ & -/-/- & $. \overline{15} / .00 / .15$ & $. \overline{00} / .13 / .13$ & $. \overline{00} / .11 / .11$ \\
\hline IQ 6y & $-/-/-$ & $-/-/-$ & $-/-/-$ & $-/-/-$ & $. \overline{84} / .00 / .84$ & $. \overline{28} / .41 / .69$ \\
\hline IQ $8 y$ & $-/-/-$ & $-/-/-$ & $-/-/-$ & $-/-/-$ & -/-/- & $. \overline{49} / .00 / .49$ \\
\hline
\end{tabular}

Note. $\mathrm{HC}=$ head circumference, $\mathrm{HG}=$ head growth, $\mathrm{IQ}=$ intelligence quotient; $\mathrm{SES}=$ socioeconomic status 


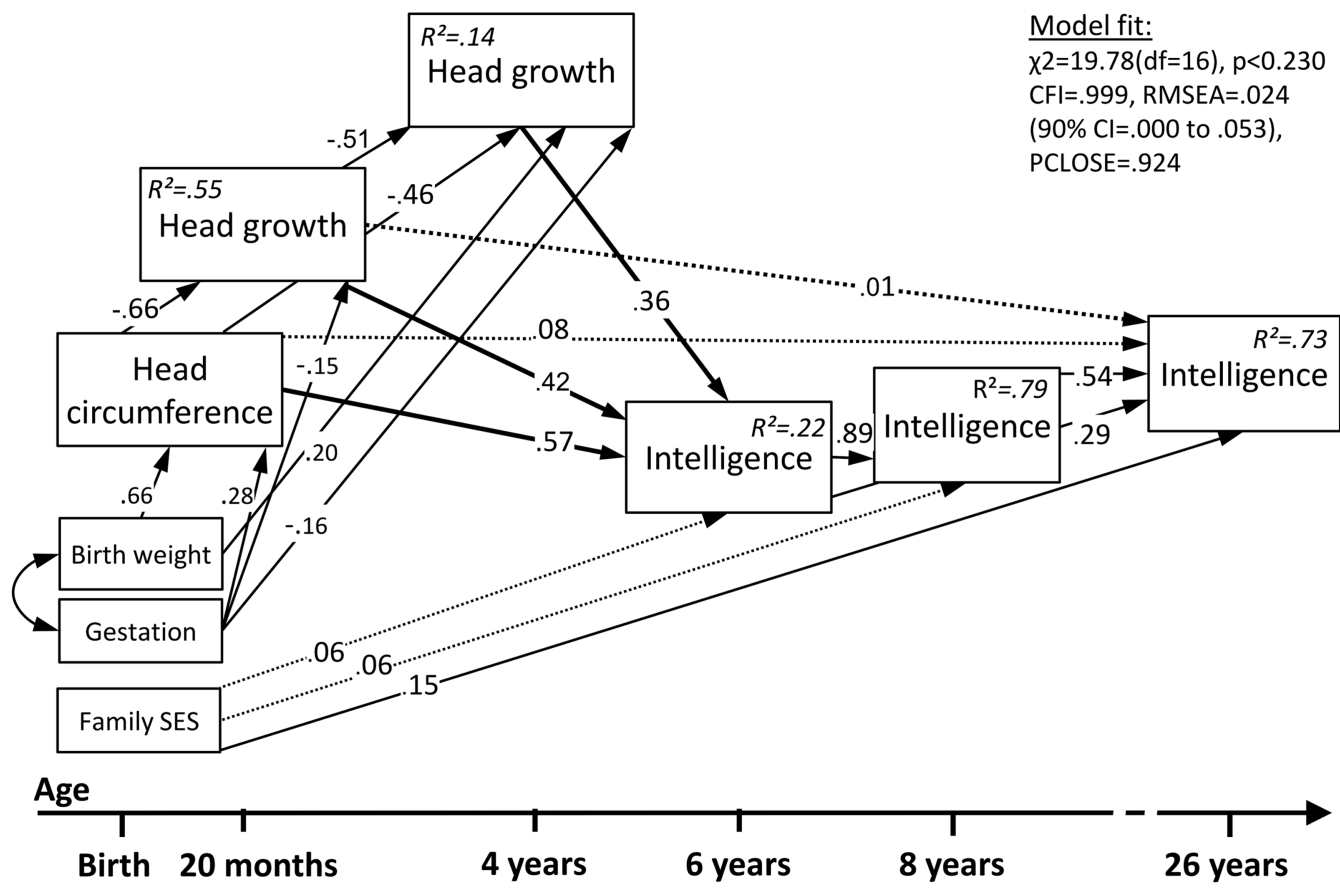

Fig. 2. Multigroup structural equation Model 2. Neurocognitive cascades of head growth and intelligence from birth to adulthood in $V P /$ $V L B W$ individuals only $(n=203)$. Please note: Solid lines represent significant paths, dotted lines represent non-significant paths that were freely estimated in the model

were fully mediated by head circumference and growth. These findings add to previous evidence about the value of repeated head circumference assessments in early childhood, in particular in VP/VLBW children, as a proxy of brain volume and screening for later intellectual impairments (Kapellou et al., 2006).
Head growth is driven by brain growth and thus an indicator of brain development (Kiesler \& Ricer, 2003). Researchers have suggested that the same genetic factors have an effect on physical (i.e., head) growth and cognitive development (Silventoinen, Iacono, Krueger, \& McGue, 2012). However, postnatal brain growth is the product of
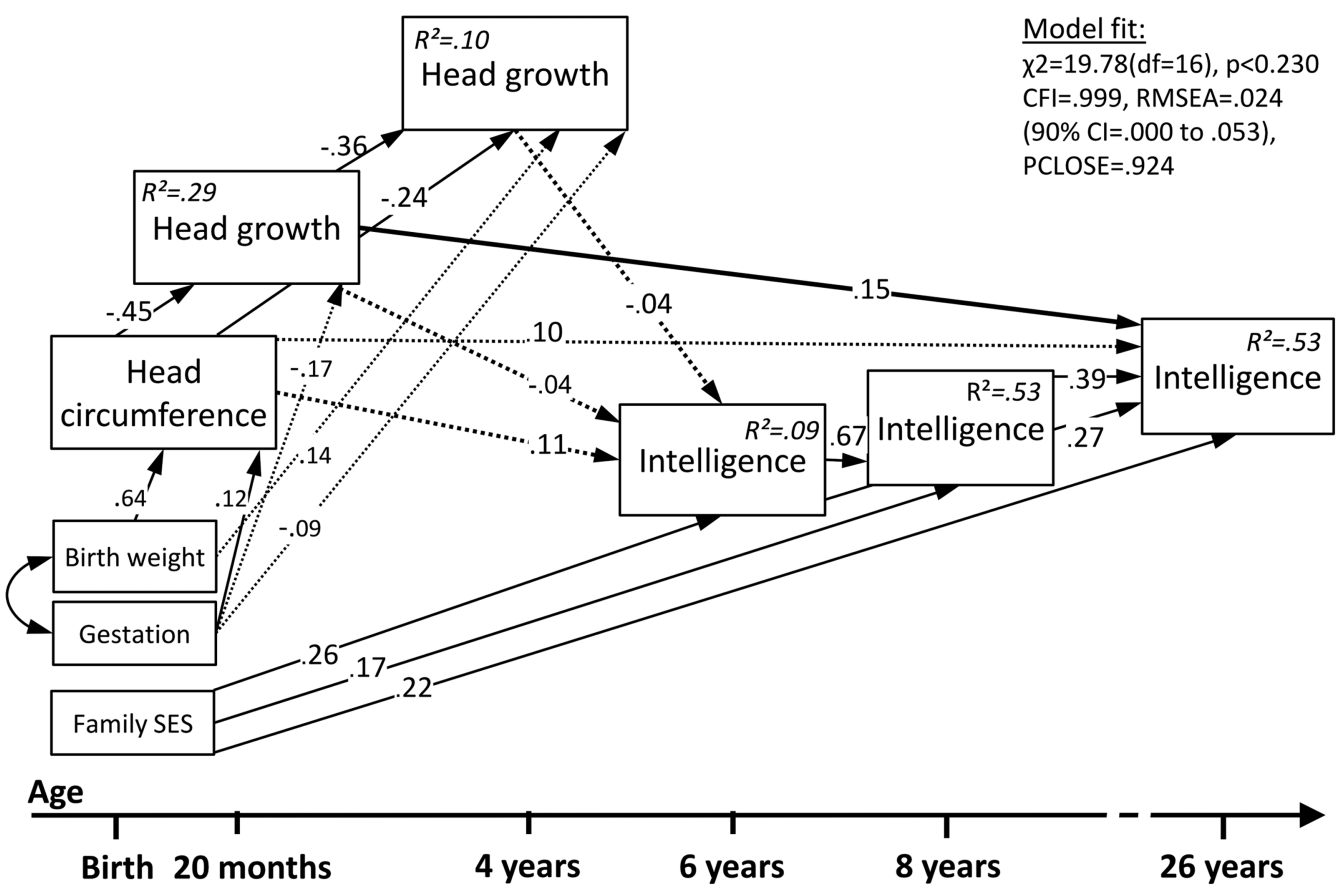

Fig. 3. Multigroup structural equation Model 3. Neurocognitive cascades of head growth and intelligence from birth to adulthood in term born individuals only $(n=198)$. Please note: Solid lines represent significant paths, dotted lines represent non-significant paths that were freely estimated in the model 
complex mechanisms, including gray matter maturation (i.e., axon and dendrite sprouting, synapse formation, cortical gyrification) and white matter formation (i.e., glial cell proliferation, myelination). Anatomically, the cranium surrounds and protects the brain and brainstem, and two thirds of its growth occur by 2 years of age (Kiesler \& Ricer, 2003).

In healthy term born infants, cortical thickness reaches $97 \%$ of adult size by age two (Lyall et al., 2015) and cortical gyrification also happens during the first 2 years ( $\mathrm{Li}$ et al., 2014), whereas cortical surface area expansion mainly drives brain growth after 2 years of age (Lyall et al., 2015). Lower gestation at birth is associated with smaller whole brain volume and growth at term-equivalent age (Kidokoro et al., 2014; Padilla, Alexandrou, Blennow, Lagercrantz, \& Ådén, 2015) and age 3 months (Holland et al., 2014). Additionally, premature birth is associated with regional brain alterations, particularly in subcortical structures such as the thalamus and striatum as well in lateral temporal and parietal cortices (Ball et al., 2012; Meng et al., 2016). These alterations persist into adulthood and are not only accompanied by widespread changes in cerebral white matter (Bäuml et al., 2015; Meng et al., 2016) but also associated with impairments in neurocognitive and behavioral development (Kidokoro et al., 2014; Parker et al., 2008).

Head circumference is an excellent indicator of cerebral volume measured with magnetic resonance imaging (MRI) in 1 - to 6-year-old children $(r=0.59-0.93)$, but its predictive validity is weaker in typically developing older children, adolescents, and adults ( $r=0.45$ to 0.69 ) (Bartholomeusz et al., 2002; Lange, Froimowitz, Bigler, \& Lainhart, 2010). Accordingly, head circumference may present an easily assessable proxy of overall brain volume, but only during the first years of life, and prediction from $\mathrm{HC}$ measurement alone is similar to that of term MRI (Anderson et al., 2017).

With regard to the timing of head growth, SEM indicated that the period from birth to 20 months of age mattered most for directly predicting later IQ development, but indirect effects of head growths from 20 months to 4 years of age were also relevant. This suggests that accelerated brain growth during the first 20 months after preterm birth may be most beneficial for age-appropriate IQ development later in life, in particular for infants born VP/VLBW. Moreover, and in accordance with studies of normative brain growth (Li et al., 2014; Lyall et al., 2015), the significant direct effect of head growth from birth to 20 months on term adults' IQs suggests that the first 2 years of postnatal life may represent a critical window for healthy brain growth and development. Thus, regular head circumference measurements, used in conjunction with other neurodevelopmental tools, may be recommended until at least 2 years of age to screen for potential brain growth delay. As a result, clinicians may need additional training to correctly administer this effective and inexpensive screening tool (James, Perszyk, MacGregor, \& Aldana, 2015).

Children's IQ development is influenced by genetic (Marioni et al., 2014) and environmental factors, such as parents' socioeconomic status (Sameroff, Seifer, Barocas,
Zax, \& Greenspan, 1987), children's home literacy environments (Jaekel, Schölmerich, Kassis, \& Leyendecker, 2011), and preschool quality (Melhuish, 2011). Accordingly, environmental stimulation may promote cognitive development of both VP/VLBW and full term children (Wolke, Jaekel, Hall, \& Baumann, 2013); thus, early identification of those children who are at-risk for low IQ would allow timely provision of resources and intervention.

Our observational study results substantiate the validity of studies that aim to improve preterm infants' long-term cognitive outcomes by supporting early head growth. Such strategies may target individualized neonatal nutrition, adaptive feeding, and breastfeeding to stimulate growth and neurodevelopmental outcomes (Belfort et al., 2016; Christmann et al., 2017). Recently, the microbiome-gut-brain axis has also received attention due to its potential for neuroprotection against white matter injury (Keunen, van Elburg, van Bel, \& Benders, 2015). Other avenues toward intervention may target "nutrition for the brain" via environmental stimulation [e.g., the neonatal intensive care unit environment (Pineda et al., 2014), sensitive parenting (Milgrom et al., 2010; Wolke et al., 2013), preschool education (McCormick et al., 2006), and family psychosocial support (Benzies, Magill-Evans, Hayden, \& Ballantyne, 2013)].

Our sample represents one of the largest whole-population longitudinal studies of neurocognitive development after VP/ VLBW birth. In total, $68 \%$ of the eligible VP/VLBW and term comparisons recruited at birth were assessed at 26 years; however, the dropout was not random, as low SES families were less likely to continue participation. Social factors are a major reason for dropout in most longitudinal studies (Hille, Elbertse, Gravenhorst, Brand, \& Verloove-Vanhorick, 2005), and analyses were controlled for SES at birth. Participants were born in Germany in 1985/1986, before the introduction of pioneering new treatments such as surfactant administration, which significantly improved high risk infants' survival rates. However, studies have shown that increased survival may not result in equivalent improvement of long-term neurocognitive outcomes (Cheong et al., 2017; Moore et al., 2012; Wolke et al., 2015); thus, the current findings may be as relevant to infants born today as to those born 30 years ago.

Changes of absolute measurements of head circumference according to postnatal age (adjusted for gestation at birth at the 5 and 20 months assessments) were included in our models. From a clinical perspective, it might be preferable to use standardized Z-scores; however, our aim was to investigate the effect of head growth on intelligence growth, while simultaneously assessing the effects of gestational age and birth weight on these growth trajectories. Our results show that the relationship between head growth and IQ development is very similar in both VP/VLBW and term individuals, but gestational age and birth weight are important factors to predict these trajectories. Standardized head circumference scores would control for gestational age but take away the variation in IQ development explained by this important factor; thus, we used raw values to model head growth over time, while timing 
of assessments at 5 and 20 months was adjusted for gestational age at birth as recommended in clinical practice (WilsonChing, Pascoe, Doyle, \& Anderson, 2014).

We were able to explain $>70 \%$ of the variation in adult intelligence; however, the majority of this was due to the longitudinal stability of IQ prediction from 6 years of age, not head circumference directly. Nevertheless, a considerable $24 \%$ of variance was explained in adult IQ if only the isolated effects of $\mathrm{HC}$ at birth and head growth were included in the model (however, this percentage of variance explained was mainly due to the VP/VLBW individuals in the sample). Intelligence is a multidimensional construct that develops through cascades (Bornstein, Hahn, \& Wolke, 2013). This is reflected in our models, with early development directly and indirectly affecting what comes later, that is, long-term effects of early head growth as marker for brain volume and function on adult IQ.

Full scale IQs are relatively stable over time (Schneider, Niklas, \& Schmiedeler, 2014), but VP/VLBW children often have limited neurocognitive resources (Jaekel, Baumann, \& Wolke, 2013) and, as a result, their average low IQs remain relatively stable from early childhood onward. Indeed, moderate prediction of adult intelligence is possible from toddler age in VP/VLBW or extremely preterm, but only from 6 years in healthy term comparison children (Breeman et al., 2015). This is reflected in our multi-group models, as VP/VLBW individuals' head circumference and growth had their strongest effects on 6 year IQ and from there on indirectly into adulthood, suggesting a rather fixed neurocognitive trajectory (Breeman et al., 2015; Eryigit Madzwamuse et al., 2015).

Similarly, the effects of family SES at birth on later IQ were larger in the healthy term born group than in VP/ VLBW (e.g., .26 vs. .06 at 6 years), indicating differences in developmental plasticity. Family SES affects cognitive development via both genetic and environmental pathways, but VP/VLBW may be more strongly affected by neonatal factors (Jaekel et al., 2013) that affect brain and head growth. Intelligence is only one marker of cognitive function, and while VP/VLBW individuals may achieve IQ test results within the average range, their daily performance in school and at work may be affected by other cognitive problems such as attention, executive function, or processing speed.

Finally, IQ assessments changed from childhood to adulthood but our instruments have been shown to deliver reliable and consistent age-appropriate estimations of intelligence (Melchers \& Preuss, 1991). Moreover, potential variations in IQ estimates across different tests (e.g., Griffiths vs. Bailey Scales) were not of concern due to the prospective inclusion of a matched healthy term comparison group with the same measures taken at all assessment points.

Model fit values indicated that the developmental pathways included in this study accurately reflect the true neurodevelopmental mechanisms in the two populations studied. Thus, our results confirm previous evidence suggesting that repeated early head circumference measurements are a valuable and easy screening tool for long-term neurocognitive risk assessment after preterm birth, in particular in light of recent findings refuting the diagnostic benefits of routine MRI on preterm infants (Edwards et al., 2018; Hintz et al., 2018).

Considering specific neurocognitive mechanisms, however, overall head circumference and brain volume are rather broad markers for cognitive functioning; thus, clinical assessments should always include other tools and a thorough review of known risk factors associated with cognitive impairment. Additional variance in individual IQ development may be explained by regional rather than global differences as well as by alterations in brain connectivity.

\section{ACKNOWLEDGMENTS}

Drs. Jaekel, Sorg, Baeuml, Bartmann, and Wolke report no conflicts of interest. This study was supported by the German Federal Ministry of Education and Science (BMBF 01ER0801; PKE24, JUG14). D.W. and P.B. are supported by EU Horizon 2020 (733280; RECAP preterm). The contents are solely the responsibility of the authors and do not necessarily represent the official view of the BMBF. We thank the pediatricians, psychologists, and research nurses who carried out the assessments, and the researchers and administrative staff of the Bavarian Longitudinal Study group who managed the data. We are deeply thankful to our participants for their time and commitment.

\section{SUPPLEMENTARY MATERIAL}

To view supplementary material for this article, please visit https://doi.org/10.1017/S135561771800084X

\section{REFERENCES}

Anderson, P.J., Treyvaud, K., Neil, J.J., Cheong, J.L.Y., Hunt, R.W., Thompson, D.K., ... Inder, T.E. (2017). Associations of newborn brain magnetic resonance imaging with long-term neurodevelopmental impairments in very preterm children. The Journal of Pediatrics, 187, 58-65. doi: 10.1016/j.jpeds.2017.04.059

Aslin, R.N., \& Fiser, J. (2005). Methodological challenges for understanding cognitive development in infants. Trends in Cognitive Sciences, 9(3), 92-98. doi: 10.1016/j.tics.2005.01.003

Ball, G., Boardman, J.P., Rueckert, D., Aljabar, P., Arichi, T., Merchant, N., ... Counsell, S.J. (2012). The effect of preterm birth on thalamic and cortical development. Cerebral Cortex, 22, 1016-1024.

Bartholomeusz, H.H., Courchesne, E., \& Karns, C.M. (2002). Relationship between head circumference and brain volume in healthy normal toddlers, children, and adults. Neuropediatrics, 33 (5), 239-241. doi: 10.1055/s-2002-36735

Bauer, A. (1988). Ein Verfahren zur Messung des fuer das Bildungsverhalten relevanten Sozial Status (BRSS) - ueberarbeitete Fassung. Frankfurt: Deutsches Institut fuer Internationale Paedagogische Forschung.

Bäuml, J.G., Daamen, M., Meng, C., Neitzel, J., Scheef, L., Jaekel, J., ... Sorg, C. (2015). Correspondence between aberrant intrinsic network connectivity and gray matter volume in the ventral brain of preterm born adults. Cerebral Cortex, 25, 4135-4145. doi:10.1093/cercor/bhu133 
Belfort, M.B., Anderson, P.J., Nowak, V.A., Lee, K.J., Molesworth, C., Thompson, D.K., ... Inder, T.E. (2016). Breast milk feeding, brain development, and neurocognitive outcomes: A 7-year longitudinal study in infants born at less than 30 weeks' gestation. The Journal of Pediatrics, 177, 133-139.e131. doi: 10.1016/j. jpeds.2016.06.045

Benzies, K., Magill-Evans, J., Hayden, K., \& Ballantyne, M. (2013). Key components of early intervention programs for preterm infants and their parents: A systematic review and meta-analysis. BMC Pregnancy and Childbirth, 13(Suppl. 1), S10.

Bornstein, M.H., Hahn, C.-S., \& Wolke, D. (2013). Systems and cascades in cognitive development and academic achievement. Child Development, 84(7), 154-162. doi:10.1111/j.14678624.2012.01849.x

Brandt, I. (1983). Griffiths Entwicklungsskalen (GES zur Beurteilung der Entwicklung in den ersten beiden Lebensjahren). Weinheim: Beltz.

Breeman, L.D., Jaekel, J., Baumann, N., Bartmann, P., \& Wolke, D. (2015). Preterm cognitive function into adulthood. Pediatrics, 136(3), 415-423. doi:10.1542/peds.2015-0608

Cheong, J.L., Anderson, P.J., Burnett, A.C., Roberts, G., Davis, N., Hickey, L., ... Doyle, L.W. (2017). Changing neurodevelopment at 8 years in children born extremely preterm since the $1990 \mathrm{~s}$. Pediatrics, 139, pii: e201664086. doi:10.1542/peds.2016-4086

Cheong, J.L., Hunt, R.W., Anderson, P.J., Howard, K., Thompson, D.K., Wang, H.X., ... Doyle, L.W. (2008). Head growth in preterm infants: Correlation with magnetic resonance imaging and neurodevelopmental outcome. Pediatrics, 121(6), e1534e1540. doi:10.1542/peds.2007-2671

Christmann, V., Roeleveld, N., Visser, R., Janssen, A.J.W.M., Reuser, J.J.C.M., van Goudoever, J.B., \& van Heijst, A.F.J. (2017). The early postnatal nutritional intake of preterm infants affected neurodevelopmental outcomes differently in boys and girls at 24 months. Acta Paediatrica, 106(2), 242-249. doi:10.1111/apa.13669

Cockerill, J., Uthaya, S., Doré, C.J., \& Modi, N. (2006). Accelerated postnatal head growth follows preterm birth. Archives of Disease in Childhood - Fetal and Neonatal Edition, 91(3), F184-F187. doi:10.1136/adc.2005.077818

Doyle, L.W., Anderson, P.J., Battin, M., Bowen, J.R., Brown, N., Callanan, C., ... Woodward, L.J. (2014). Long term follow up of high risk children: Who, why and how? BMC Pediatrics, 14(1), 279. doi:10.1186/1471-2431-14-279

Edwards, A.D., Redshaw, M.E., Kennea, N., Rivero-Arias, O., Gonzales-Cinca, N., Nongena, P., ... Counsell, S. (2018). Effect of MRI on preterm infants and their families: A randomised trial with nested diagnostic and economic evaluation. Archives of Disease in Childhood. Fetal and Neonatal Edition, 103(1), F15F21. doi:10.1136/archdischild-2017-313102

Eryigit Madzwamuse, S., Baumann, N., Jaekel, J., Bartmann, P., \& Wolke, D. (2015). Neuro-cognitive performance of very preterm or very low birth weight adults at 26 years. Journal of Child Psychology and Psychiatry, 56(8), 857-864.

Fenton, T.R., \& Kim, J.H. (2013). A systematic review and metaanalysis to revise the Fenton growth chart for preterm infants. BMC Pediatrics, 13(1), 59. doi:10.1186/1471-2431-13-59

Gale, C.R., O'Callaghan, F.J., Bredow, M., \& Martyn, C.N. (2006). The influence of head growth in fetal life, infancy, and childhood on intelligence at the ages of 4 and 8 years. Pediatrics, 118(4), 1486-1492. doi:10.1542/peds.2005-2629

Garcia-Alix, A., Saenz-de Pipaon, M., Martinez, M., SalasHernandez, S., \& Quero, J. (2004). [Ability of neonatal head circumference to predict long-term neurodevelopmental outcome]. Revista de Neurologia, 39(6), 548-554.

Hack, M., Taylor, H.G., Drotar, D., Schluchter, M., Cartar, L., Wilson-Costello, D., ... Morrow, M. (2005). Poor predictive validity of the Bayley Scales of Infant Development for cognitive function of extremely low birth weight children at school age. Pediatrics, 116(2), 333-341. doi:10.1542/peds.2005-0173

Hille, E.T.M., Elbertse, L., Gravenhorst, J.B., Brand, R., \& Verloove-Vanhorick, S.P. (2005). Nonresponse bias in a follow-up study of 19-year-old adolescents born as preterm infants. Pediatrics, 116, e662-e666. doi:10.1542/peds.20050682

Hintz, S.R., Vohr, B.R., Bann, C.M., Taylor, H.G., Das, A., Gustafson, K.E., ... Higgins, R.D. (2018). Preterm neuroimaging and school-age cognitive outcomes. Pediatrics. 142, pii: e20174058. doi:10.1542/peds.2017-4058

Holland, D., Chang, L., Ernst, T.M., Curran, M., Buchthal, S.D., Alicata, D., ... Dale, A.M. (2014). Structural growth trajectories and rates of change in the first 3 months of infant brain development. JAMA Neurology, 71(10), 1266-1274. doi:10.1001/jamaneurol.2014.1638

Jaekel, J., Baumann, N., \& Wolke, D. (2013). Effects of gestational age at birth on cognitive performance: A function of cognitive workload demands. PLoS One, 8(5), e65219. doi:10.1371/ journal.pone.0065219

Jaekel, J., Schölmerich, A., Kassis, W., \& Leyendecker, B. (2011). Parental bookreading as a resource for pre-schoolers' cognitive skills in Turkish migrant and German non-migrant families. International Journal of Developmental Science, 5, 1-13.

James, H.E., Perszyk, A.A., MacGregor, T.L., \& Aldana, P.R. (2015). The value of head circumference measurements after 36 months of age: A clinical report and review of practice patterns. Journal of Neurosurgery. Pediatrics, 16(2), 186-194. doi:10.3171/2014.12.peds14251

Kapellou, O., Counsell, S.J., Kennea, N., Dyet, L., Saeed, N., Stark, J., ... Edwards, A.D. (2006). Abnormal cortical development after premature birth shown by altered allometric scaling of brain growth. PLoS Med, 3(8), e265.

Keunen, K., van Elburg, R.M., van Bel, F., \& Benders, M.J.N.L. (2015). Impact of nutrition on brain development and its neuroprotective implications following preterm birth. Pediatric Research, 77(1-2), 148-155. doi:10.1038/pr.2014.171

Kidokoro, H., Anderson, P.J., Doyle, L.W., Woodward, L.J., Neil, J. J., \& Inder, T.E. (2014). Brain injury and altered brain growth in preterm infants: Predictors and prognosis. Pediatrics, 134(2), e444-e453. doi:10.1542/peds.2013-2336

Kiesler, J., \& Ricer, R. (2003). The abnormal fontanel. American Family Physician, 67(12), 2547-2552.

Lange, N., Froimowitz, M.P., Bigler, E.D., \& Lainhart, J.E. (2010). Associations between IQ, total and regional brain volumes and demography in a large normative sample of healthy children and adolescents. Developmental Neuropsychology, 35(3), 296-317. doi:10.1080/87565641003696833

Li, G., Wang, L., Shi, F., Lyall, A.E., Lin, W., Gilmore, J.H., \& Shen, D. (2014). Mapping longitudinal development of local cortical gyrification in infants from birth to 2 years of age. The Journal of Neuroscience, 34(12), 4228-4238. doi:10.1523/ jneurosci.3976-13.2014

Lyall, A.E., Shi, F., Geng, X., Woolson, S., Li, G., Wang, L., ... Gilmore, J.H. (2015). Dynamic development of regional cortical thickness and surface area in early childhood. Cerebral Cortex, 25(8), 2204-2212. doi:10.1093/cercor/bhu027 
Makropoulos, A., Aljabar, P., Wright, R., Hüning, B., Merchant, N., Arichi, T., ... Rueckert, D. (2016). Regional growth and atlasing of the developing human brain. NeuroImage, 125, 456-478. doi: http://dx.doi.org/10.1016/j.neuroimage.2015.10.047

Marioni, R.E., Davies, G., Hayward, C., Liewald, D., Kerr, S.M., Campbell, A., ... Deary, I.J. (2014). Molecular genetic contributions to socioeconomic status and intelligence. Intelligence, 44 , 26-32. doi: http://dx.doi.org/10.1016/j.intell.2014.02.006

McCormick, M.C., Brooks-Gunn, J., Buka, S.L., Goldman, J., Yu, J., Salganik, M., ... Casey, P.H. (2006). Early intervention in low birth weight premature infants: Results at 18 years of age for the Infant Health and Development Program. Pediatrics, 117(3), 771-780.

Melchers, P., \& Preuss, U. (1991). K-ABC: Kaufman Battery for Children: Deutschsprachige Fassung. Frankfurt, AM: Swets \& Zeitlinger.

Melhuish, E.C. (2011). Preschool matters. Science, 333(6040), 299300. doi:10.1126/science.1209459

Meng, C., Bauml, J.G., Daamen, M., Jaekel, J., Neitzel, J., Scheef, L., ... Sorg, C. (2016). Extensive and interrelated subcortical white and gray matter alterations in preterm-born adults. Brain Structure \& Function, 221(4), 2109-2121. doi:10.1007/s00429015-1032-9

Milgrom, J., Newnham, C., Anderson, P.J., Doyle, L.W., Gemmill, A.W., Lee, K., ... Inder, T. (2010). Early sensitivity training for parents of preterm infants: Impact on the developing brain. Pediatric Research, 67(3), 330-335.

Moore, T., Hennessy, E.M., Myles, J., Johnson, S., Draper, E.S., Costeloe, K.L., \& Marlow, N. (2012). Neurological and developmental outcome in extremely preterm children born in England in 1995 and 2006: The EPICure studies. BMJ, 345, e7961. doi:10.1136/bmj.e7961

Padilla, N., Alexandrou, G., Blennow, M., Lagercrantz, H., \& Ådén, U. (2015). Brain growth gains and losses in extremely preterm infants at term. Cerebral Cortex, 25(7), 1897-1905. doi:10.1093/ cercor/bht431

Parker, J., Mitchell, A., Kalpakidou, A., Walshe, M., Jung, H.-Y., Nosarti, C., ... Allin, M. (2008). Cerebellar growth and behavioural \& neuropsychological outcome in preterm adolescents. Brain, 131, 1344-1351.

Pineda, R.G., Neil, J., Dierker, D., Smyser, C.D., Wallendorf, M., Kidokoro, H., ... Inder, T. (2014). Alterations in brain structure and neurodevelopmental outcome in preterm infants hospitalized in different neonatal intensive care unit environments. The Journal of Pediatrics, 164(1), 52-60.e52. doi: http://dx.doi.org/ 10.1016/j.jpeds.2013.08.047

Räikkönen, K., Forsén, T., Henriksson, M., Kajantie, E., Heinonen, K., Pesonen, A.-K., ... Eriksson, J.G. (2009). Growth trajectories and intellectual abilities in young adulthood: The Helsinki Birth Cohort Study. American Journal of Epidemiology, 170(4), 447455. doi:10.1093/aje/kwp132

Sameroff, A.J., Seifer, R., Barocas, R., Zax, M., \& Greenspan, S. (1987). Intelligence quotient scores of 4-year-old children: Social-environmental risk factors. Pediatrics, 79(3), 343-350.
Sammallahti, S., Heinonen, K., Andersson, S., Lahti, M., Pirkola, S., Lahti, J., ... Raikkonen, K. (2017). Growth after late-preterm birth and adult cognitive, academic, and mental health outcomes. Pediatric Research, 81, 767-774. doi:10.1038/pr.2016.276

Sammallahti, S., Pyhala, R., Lahti, M., Lahti, J., Pesonen, A.K., Heinonen, K., ... Raikkonen, K. (2014). Infant growth after preterm birth and neurocognitive abilities in young adulthood. The Journal of Pediatrics, 165(6), 1109-1115.e1103. doi:10.1016/j.jpeds.2014.08.028

Schneider, W., Niklas, F., \& Schmiedeler, S. (2014). Intellectual development from early childhood to early adulthood: The impact of early IQ differences on stability and change over time. Learning and Individual Differences, 32, 156-162. doi: 10.1016/ j.lindif.2014.02.001

Silventoinen, K., Iacono, W.G., Krueger, R., \& McGue, M. (2012). Genetic and environmental contributions to the association between anthropometric measures and IQ: A study of Minnesota twins at age 11 and 17. Behavior Genetics, 42(3), 393-401. doi:10.1007/s10519-011-9521-y

Usami, S., Hayes, T., \& McArdle, J. (2017). Fitting structural equation model trees and latent growth curve mixture models in longitudinal designs: The influence of model misspecification. Structural Equation Modeling: A Multidisciplinary Journal, 24 (4), 585-598. doi:10.1080/10705511.2016.1266267

Von Aster, M., Neubauer, A., \& Horn, R. (2006). Wechsler Intelligenztest für Erwachsene (WIE) [Wechsler Adult Intelligence Scale (WAIS III)]. Frankfurt/Main, Germany: Harcourt Test Services.

WHO. (2007). WHO Child Growth Standards: Head circumferencefor-age, arm circumference-for-age, triceps skinfold-for-age and subscapular skinfold-for-age: Methods and development. Retrieved from http://www.who.int/childgrowth/publications/en

Wilson-Ching, M., Pascoe, L., Doyle, L.W., \& Anderson, P.J. (2014). Effects of correcting for prematurity on cognitive test scores in childhood. Journal of Paediatrics and Child Health, 50 (3), 182-188. doi:doi:10.1111/jpc.12475

Wolke, D., Jaekel, J., Hall, J., \& Baumann, N. (2013). Effects of sensitive parenting on the academic resilience of very preterm and very low birth weight adolescents. Journal of Adolescent Health, 53(5), 642-647.

Wolke, D., \& Meyer, R. (1999). Cognitive status, language attainment, and prereading skills of 6-year-old very preterm children and their peers: The Bavarian Longitudinal Study. Developmental Medicine \& Child Neurology, 41, 94-109.

Wolke, D., Strauss, V.Y.-C., Johnson, S., Gilmore, C., Marlow, N., \& Jaekel, J. (2015). Universal gestational age effects on cognitive and basic mathematic processing: 2 cohorts in 2 countries. The Journal of Pediatrics, 166(6), 1410-1416. e1412.

Wright, C.M., \& Emond, A. (2015). Head growth and neurocognitive outcomes. Pediatrics, 135(6), e1393-e1398. doi:10.1542/ peds.2014-3172

Zander, J., Holzmann, K., \& Selbmann, H.K. (1989). Materialien aus der bayerischen Perinatalerhebung zur Problematik der Sectiofrequenz [Data from the Bavarian perinatal survey on the problem of the incidence of cesarean section]. Geburtshilfe Frauenheilkunde, 49(4), 328-336. 